\title{
Influence of thoracic spine postural disorders on cardiorespiratory parameters in children and adolescents with cystic fibrosis
}

\author{
Renata Tiemi Okuro, ${ }^{1}$ Ester Piacentini Côrrea, ${ }^{2}$ Patrícia Blau Margosian Conti, ${ }^{3}$ \\ José Dirceu Ribeiro, ${ }^{4}$ Maria Ângela Gonçalves Oliveira Ribeiro, ${ }^{5}$ Camila Isabel Santos Schivinski ${ }^{6}$
}

\begin{abstract}
Objectives: To assess the impact of increased thoracic kyphosis on pulmonary function and functional capacity in children and adolescents with cystic fibrosis (CF) and to verify the influence of disease severity, age and nutritional status on this deformity.

Method: This was a cross-sectional, analytical study conducted at a university hospital. It included CF patients with confirmed diagnosis and without pulmonary exacerbation. The sample was submitted to postural assessment, spirometry $\left(\mathrm{FEV}_{1}, \mathrm{FVC}\right.$ and $\left.\mathrm{FEV}_{1} / \mathrm{FVC}\right)$ and 6-minute walk test distance (6-MWT distance). Data were analyzed using the Mann Whitney test, Spearman correlation and logistic regression.

Results: Forty-two patients were enrolled, $61.9 \%$ presented increase of thoracic kyphosis. There was no difference in values of $\mathrm{FEV}_{1}, \mathrm{FVC}, \mathrm{FEV}_{1} / \mathrm{FVC}$ and 6-MWT distance between the groups with or without thoracic kyphosis $(p=0.407 ; p=0.756 ; p=0.415 ; p=0.294)$. In the group without alteration, patients with more disease severity had a mean $\mathrm{FEV}_{1}$ of $74.1 \pm 21.9 \%$ and $\mathrm{FVC}$ of $79.8 \pm 18.7 \%$ while in those of lesser severity higher values were found $(95.6 \pm 12.2 \%$ and $97.6 \pm 13.2 \%$, respectively) $(p=0.027$ and $p=0.027)$. The presence of kyphosis was correlated with age $(p=0.048)$ but not with severity $(p=0.151)$ and body mass index $(p=0.088)$.

Conclusions: There was a high prevalence of increased thoracic kyphosis in children and adolescents with $\mathrm{CF}$. The deformity did not affect pulmonary function and functional capacity and there was no relationship with disease severity. Regardless of posture, worsening of disease severity determined worsening of pulmonary function.
\end{abstract}

J Pediatr (Rio J). 2012;88(4):310-6: Posture, cystic fibrosis, pulmonary function.

\section{Introduction}

The increase in life expectancy in cystic fibrosis (CF) involves the development of secondary complications related to the musculoskeletal system. ${ }^{1}$ The occurrence of changes in body posture that can harm functions related to the cardiopulmonary system is among them. ${ }^{2}$

This is because postural abnormalities have a strong influence on the respiratory effort, as this determines a permanent stimulus on the musculoskeletal support, potentially aggressive in age groups in development. 3,4

The trunk, which involves muscles and the thoracic spine, has a dual relationship with postural support and ventilation. This dual function requires that it regulates both postural needs and the needs of the respiratory system. ${ }^{5}$

1. MSc in Sciences. Universidade Estadual de Campinas (UNICAMP), Campinas, SP, Brazil.

2. Master's candidate, Saúde da Criança e do Adolescente. UNICAMP, Campinas, SP, Brazil.

3. MSc, Saúde da Criança e do Adolescente. UNICAMP, Campinas, SP, Brazil.

4. Associate tenured professor, Departamento de Pediatria, Faculdade de Ciências Médicas (FCM), UNICAMP, Campinas, SP, Brazil. Laboratório de Fisiologia Pulmonar, Centro de Investigação em Pediatria da FCM, UNICAMP, Campinas, SP, Brazil.

5. PhD, Saúde da Criança e do Adolescente. UNICAMP, Campinas, SP, Brazil. Coordinator, Serviço de Fisioterapia em Pediatria, FCM, Hospital de Clínicas, UNICAMP, Campinas, SP, Brazil. Coordinator, Pós-Graduação em Fisioterapia Pediátrica, UNICAMP, Campinas, SP, Brazil.

6. PhD, Saúde da Criança e do Adolescente, UNICAMP, Campinas, SP, Brazil. Professor Graduação e Pós-Graduação em Fisioterapia, Universidade do Estado de Santa Catarina (UDESC), Florianópolis, SC, Brazil.

No conflicts of interest declared concerning the publication of this article.

Suggested citation: Okuro RT, Côrrea EP, Conti PB, Ribeiro JD, Ribeiro MA, Schivinski Cl. Influence of thoracic spine postural disorders on cardiorespiratory parameters in children and adolescents with cystic fibrosis. J Pediatr (Rio J). 2012;88(4):310-6.

Manuscript submitted Jan 17 2012, accepted for publication Apr 252012.

http://dx.doi.org/10.2223/JPED.2206 
In $\mathrm{CF}$, pulmonary disease exerts a positive pressure, repeated over and over the thoracic framework, resulting in a thoracic kyphosis. This deformity is the result of the obstructive process and the constant coughing episodes caused by the hypersecretion characteristic of the disease. Its presence may contribute to declining respiratory function. ${ }^{6}$

It is recommended that interventions be performed in an attempt to prevent and/or minimize emerging postural abnormalities. Early treatment is crucial in order to minimize the impairment of respiratory function. The pre-puberty phase (8-12 years) is described as the best period to begin this closer attention, because the growth phase is the most suitable for any intervention. ${ }^{6}$

Therefore, the objective of this study was to assess the impact of increased thoracic kyphosis on respiratory function and on the functional capacity of children and adolescents with CF and to assess the influence of disease severity, age and nutritional aspects on the presence of this deformity.

\section{Method}

A cross-sectional analytical study was carried out at the Cystic Fibrosis Clinic of the Department of Pediatrics, Hospital de Clinicas da Universidade Estadual de Campinas (UNICAMP), Brazil. Included subjects were children and adolescents from 7 to 19 years, followed in regular service, with a diagnosis of CF confirmed by clinical history, altered sweat test (chloride greater than $60 \mathrm{mmol} / \mathrm{L}$ ) in at least two samples and molecular genetic study. The excluded patients were those dependent on oxygen and those in acute pulmonary exacerbation, according to the Cystic Fibrosis Clinical Score ${ }^{7}$ and Cystic Fibrosis Foundation scores $^{8}$. These are instruments routinely used in outpatient consultations. ${ }^{9}$

The CF outpatient service provides assistance to approximately 150 children and adolescents. All patients followed up by the service within the range defined by the study group were invited to participate in the study, which was performed from January to December, 2011.

The sample was submitted to postural assessment through the New York test (NYT), ${ }^{10,11}$ examination of pulmonary function by spirometry and the 6-minute walk test (6MWT). Height and weight anthropometric data, as well as the computation of the body mass index (BMI) were also recorded.

NYT is an objective method of assessing posture that includes 13 body segments. It has a scoring system that allows quantitative analysis and the rating of the assessed postural disorder. Each body segment is scored according to the suitability of their alignment ( 5 points - normal pattern; 3 - moderate change; and 1 - severe). At the end of the assessment the points of all segments are added up, and the individual's posture is classified as normal (56-65 points), moderate (40-55) or severe (1-39). ${ }^{11}$ This study specifically examined the position of the thoracic spine in lateral view, which determines the degree of curvature of this segment (normal, with a slight increase or a high degree of kyphosis). This change was also classified as normal, moderate or severe, according to the NYT, and patients were grouped according to presence (NYT moderate or severe) or absence (normal NYT) of increased thoracic kyphosis. They were labeled as group with thoracic kyphosis and group without it, respectively. For data analysis, this variable was considered as qualitative.

Pulmonary function was assessed by spirometry (Medgraphics CPFS/D spirometer) in the Pulmonary Function Laboratory, School of Medical Sciences, UNICAMP, following regulations by the American Thoracic Society (ATS, 1995). ${ }^{12}$ The percentage of the predicted value of the variables of forced expiratory volume in one second $\left(\mathrm{FEV}_{1}\right)$ and forced vital capacity (FVC) was considered. A cutoff point of $80 \%$ was considered to divide the sample below the predicted value (less than $80 \%$ ) and above it (80\%).

After a 15 minutes rest, the 6MWT was performed to assess the functional capacity of patients with CF. 6MWT was also performed following ATS' recommendations (ATS, 2002).13 The distance covered (DC) was recorded. The predicted distance for each participant was calculated according to Prienitz et al. ${ }^{14}$ For data analysis, patients were grouped according to test performance and DC (DC: below and above the predicted).

The severity of cystic fibrosis was also considered using the Shwachman score (SS) modified by Doershuk. ${ }^{15}$ The SS covers items related to general activity, physical examination, nutrition and radiological findings, with a range from 20 to 100 points. Patients were classified as severe (score below 40), moderate (between 40 and 55), medium (from 56 to 70), good (between 71 and 85) and excellent (from 86 to 100 points). For data analysis, the sample was divided into two groups: the groups of lesser severity (patients classified as good or excellent by SS) and of greater severity (classified as severe, moderate and medium), 15 and considered dichotomized.

The data were processed using the Statistical Package for Social Sciences 16.0 computer program (SPSS Inc., Chicago, IL, USA). The frequency of the variables for characterizing the sample was determined. The lack of data normality was verified by using the KolmogorovSmirnov and Shapiro-Wilk test. The comparison of the spirometric variables (FVC, $\mathrm{FEV}_{1}, \mathrm{FEV}_{1} / \mathrm{FVC}$ ) and of DC in 6MWT between groups with and without thoracic kyphosis was made by using the nonparametric Mann-Whitney test for independent samples. The same test was used to compare the same variables in accordance with the severity of the groups. The Spearman correlation test 
was used to determine the influence of thoracic kyphosis on spirometric parameters, BMI, age and severity. The relationship between the presence of kyphosis and the spirometric variables ( $\mathrm{FEV}_{1}$ and $\mathrm{FVC}$ ) and functional (DC in 6MWT) was analyzed by univariate logistic regression, followed by multivariate, using the Forward Wald method. Thoracic kyphosis was considered as an independent variable, and $\mathrm{FEV}_{1}, \mathrm{FVC}$ and DC in 6MWT were considered as dependent variables. The significance level adopted was $5 \%$.

The project was approved by the Research Ethics Committee of the School of Medical Sciences, UNICAMP ( $n$. $172 / 2010)$. All study participants had a term of informed consent signed by parents or guardians.

\section{Results}

The study included 42 children and adolescents from 7 to 19 years, mean age $12.47 \pm 3.43$ years. Patients had a minimum of $12 \mathrm{~kg}$ and a maximum of $64.4 \mathrm{~kg}$ (mean $30.82 \pm 14.71 \mathrm{~kg}$ ) and a mean height of $1.32 \pm 0.23$ meters.

Table 1 presents the characteristics of the sample concerning demographics, gender, age, disease severity, postural and thoracic spine pattern, spirometry and DC in 6MWT.

The relation between the presence of alterations in the thoracic spine, according to the NYT classification, and the variables FEV 1 , FVC, FEV 1 /FVC and DC in 6MWT was analyzed. The mean values of $\mathrm{FEV}_{1}$ in the group without increased thoracic kyphosis $(n=16)$ was $84.8 \pm 20.4$ (percentage compared to the predicted), and in the group with increased thoracic kyphosis $(n=26)$ it was an average of $78.8 \pm 20.7$. This difference was not statistically significant ( $p=0.407$ ). Regarding the values of FVC, the groups with and without increased thoracic kyphosis had averages of $88.7 \pm 18.1$ and $85.5 \pm 18.4$, respectively $(p=0.756)$.

The mean values of $\mathrm{FEV}_{1} / \mathrm{FVC}$ for the group without thoracic kyphosis was $95.1 \pm 10.6$ (percent relative to the predicted value), and in the group with thoracic kyphosis it increased to $91.7 \pm 13.7$. This difference was not statistically significant $(p=0.415)$. The mean DC in 6MWT in groups without and with increased thoracic

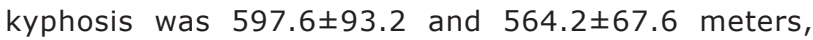
respectively ( $p=0.294)$.

Tables 2 and 3 refer to the distribution of values of $\mathrm{FEV}_{1}$, FVC, FEV $_{1} /$ FVC and DC in 6MWT compared to SS levels of disease severity, present in the groups with and without alterations of the thoracic spine.

In the group without thoracic kyphosis, patients with more severe CF had a mean $\mathrm{FEV}_{1}$ of $74.1 \pm 21.9 \%$, while the group of lesser severity showed higher values (95.6 $12.2 \%)$. This difference was statistically significant $(p=0.027)$. In
FVC, the group without thoracic kyphosis and classified as less severe had a mean of $97.6 \pm 13.2 \%$ of the predicted, and the more severe group, $79.8 \pm 18.7 \%(p=0.027)$. The FEV $1 /$ FVC ratio in the group without increased thoracic kyphosis and less severe had a mean of $98.3 \pm 8.6$, whereas in the more severe group the mean was $91.9 \pm 12.1(p=0.141)$. In the group with increased thoracic kyphosis, the group of lesser severity had a $\mathrm{FEV}_{1} / \mathrm{FVC}$ score ratio of $93.7 \pm 14.1$, while the group of greater severity, an average $87.2 \pm 12.5$ $(p=0.120)$. These data are presented in Table 2 .

There was no difference in DC in 6MWT and the level of severity of disease (lesser and greater severity) in the groups

Table 1 - Sample characterization concerning anthropometric data, sex, age, disease severity, postural and thoracic spine pattern, spirometry and distance covered in the 6 -minute walk test

\begin{tabular}{|c|c|c|}
\hline Variable & $\mathbf{n}$ & $\%$ \\
\hline \multicolumn{3}{|l|}{ Sex } \\
\hline Male & 19 & 45.2 \\
\hline Female & 23 & 54.8 \\
\hline \multicolumn{3}{|l|}{ Age (years) } \\
\hline Under or equal to 12 years & 20 & 47.6 \\
\hline Over 12 years & 22 & 52.4 \\
\hline \multicolumn{3}{|l|}{ BMI } \\
\hline$<$ percentile 5 & 12 & 28.6 \\
\hline Between percentile 5 and 50 & 23 & 54.8 \\
\hline Between percentile 50 and 85 & 7 & 16.7 \\
\hline Above percentile 85 & 0 & 0 \\
\hline \multicolumn{3}{|l|}{ Severity score } \\
\hline Excellent & 4 & 9.5 \\
\hline Good & 22 & 52.4 \\
\hline Medium & 13 & 30.0 \\
\hline Moderate & 3 & 7.1 \\
\hline Severe & 0 & 0 \\
\hline \multicolumn{3}{|l|}{ Global posture } \\
\hline Normal & 8 & 19.0 \\
\hline Moderate & 26 & 61.9 \\
\hline Severe & 8 & 19.0 \\
\hline \multicolumn{3}{|l|}{ Thoracic spine } \\
\hline Without thoracic kyphosis & 16 & 38.1 \\
\hline With thoracic kyphosis & 26 & 61.9 \\
\hline \multicolumn{3}{|l|}{$\mathrm{FEV}_{1}$} \\
\hline Below the predicted & 19 & 45.2 \\
\hline Normal/above the predicted & 23 & 54.8 \\
\hline \multicolumn{3}{|l|}{ FVC } \\
\hline Below the predicted & 13 & 31.0 \\
\hline Normal/above the predicted & 29 & 69.0 \\
\hline \multicolumn{3}{|l|}{$\mathrm{FEV}_{1} / \mathrm{FVC}$} \\
\hline Below the predicted & 8 & 19.0 \\
\hline Normal/above the predicted & 34 & 81.0 \\
\hline \multicolumn{3}{|l|}{ DC in $6 M W T$} \\
\hline Below the predicted & 23 & 54.8 \\
\hline Normal/above the predicted & 19 & 45.2 \\
\hline
\end{tabular}

$\mathrm{BMI}=$ body mass index; $\mathrm{DC}$ in 6MWT = distance covered in the 6-minute walk test; FEV $_{1}=$ forced expiratory volume in the first second; FVC = forced vital capacity. 
without and with thoracic kyphosis (639.8 \pm 105.2 versus $555.5 \pm 59.1$ meters, $p=0.093$; and $559.7 \pm 64.3$ versus $574.5 \pm 78.0$ meters, $\mathrm{p}=0.868$, respectively) (Table 3 )

There was a correlation between thoracic kyphosis and age $(r=0.308, p=0.048)$. BMI $(r=0.088, p=0.581)$ and disease severity $(r=-0.151, p=0.339)$ did not correlate with the deformity.

After conducting univariate logistic regression, it was found that there was a harmful association between DC in 6MWT and children with kyphosis, as well as with FEV $_{1}$ (odds ratio $>1.00$ ). Patients with abnormal chest showed DC below predicted and $\mathrm{FEV}_{1}$ below $80 \%$ (Table 4). In this study, a patient with CF and kyphosis showed a 0.972 chance having $\mathrm{FEV}_{1}$ below the predicted and 0.2513 of reaching a lower DC in 6MWT compared to a CF without kyphosis. For FVC, the result was -0.0225 . In the application of multivariate logistic regression, none of the variables remained in the model.

Table 2 - Distribution of forced expiratory volume in the first second and forced vital capacity values in relation to cystic fibrosis in groups with and without thoracic kyphosis

\begin{tabular}{|c|c|c|c|c|c|c|}
\hline Variable & $\mathbf{n}$ & Mean & SD & Minimum & Maximum & $\mathbf{p}$ \\
\hline \multicolumn{7}{|c|}{$\mathrm{FEV}_{1}$} \\
\hline Lesser severity & 8 & 95.6 & 12.2 & 80.0 & 115.0 & \\
\hline Greater severity & 8 & 74.1 & 21.9 & 38.0 & 112.0 & 0.027 \\
\hline \multicolumn{7}{|c|}{ With thoracic kyphosis } \\
\hline Lesser severity & 18 & 80.3 & 22.5 & 32.0 & 112.0 & \\
\hline Greater severity & 8 & 75,3 & 16.9 & 41.0 & 94.0 & 0.487 \\
\hline \multicolumn{7}{|c|}{ FVC } \\
\hline \multicolumn{7}{|c|}{ Without thoracic kyphosis } \\
\hline Lesser severity & 8 & 97.6 & 13.2 & 81.0 & 118.0 & \\
\hline Greater severity & 8 & 79.8 & 18.7 & 52.0 & 115.0 & 0.027 \\
\hline \multicolumn{7}{|c|}{ With thoracic kyphosis } \\
\hline Lesser severity & 18 & 85.2 & 19.6 & 53.0 & 118.0 & \\
\hline Greater severity & 8 & 86.2 & 16.5 & 63.0 & 116.0 & 0.846 \\
\hline \multicolumn{7}{|c|}{$\mathrm{FEV}_{1} / \mathrm{FVC}$} \\
\hline \multicolumn{7}{|c|}{ Without thoracic kyphosis } \\
\hline Lesser severity & 8 & 98.3 & 8.6 & 83.3 & 106.9 & \\
\hline Greater severity & 8 & 91.9 & 12.1 & 73.1 & 104.5 & 0.141 \\
\hline \multicolumn{7}{|c|}{ With thoracic kyphosis } \\
\hline Lesser severity & 18 & 93.7 & 14.1 & 60.4 & 112.0 & \\
\hline Greater severity & 8 & 87.2 & 12.5 & 65.1 & 102.9 & 0.120 \\
\hline
\end{tabular}

$\mathrm{FEV}_{1}=$ forced expiratory volume in the first second; FVC = forced vital capacity; $\mathrm{p}=$ non-parametric Mann-Whitney test probability; SD = standard deviation. Values given in percent in relation to the predicted.

Table 3 - Distribution of distance covered in the 6-minute walk teste values in relation to cystic fibrosis severity in groups with and without thoracic kyphosis

\begin{tabular}{|c|c|c|c|c|c|c|}
\hline DC in 6MWT & $\mathbf{n}$ & Mean & SD & Minimum & Maximum & $\mathbf{p}$ \\
\hline \multicolumn{7}{|c|}{ Without thoracic kyphosis } \\
\hline Lesser severity & 8 & 639.8 & 105.2 & 486.0 & 772.8 & \\
\hline Greater severity & 8 & 555.5 & 59.1 & 429.6 & 630.0 & 0.093 \\
\hline \multicolumn{7}{|c|}{ With thoracic kyphosis } \\
\hline Lesser severity & 18 & 559.7 & 64.3 & 415.2 & 643.0 & \\
\hline Greater severity & 8 & 574.5 & 78.0 & 502.8 & 733.3 & 0.868 \\
\hline
\end{tabular}

$\mathrm{DC}$ in $6 \mathrm{MWT}=$ distance covered in the 6-minute walk test; $\mathrm{p}=$ non-parametric Mann-Whitney test probability; SD = standard deviation.

Values given in meters. 
Table 4 - Distribution of frequencies and raw odds ratio in relation to spirometric variables (forced vital capacity and forced expiratory volume in the first second) and distance covered in the 6-minute walking test

\begin{tabular}{|c|c|c|c|c|c|c|}
\hline Variable & $\mathbf{n}$ & $\begin{array}{c}\text { With kyphosis } \\
\text { n (\%) }\end{array}$ & $\begin{array}{c}\text { Without kyphosis } \\
\text { n (\%) }\end{array}$ & OR & $95 \% \mathrm{CI}$ & p* \\
\hline \multicolumn{7}{|l|}{$\mathrm{FEV}_{1}$} \\
\hline Above $80 \%$ & 23 & $14(60.8)$ & $9(39.2)$ & 1 & $0.3148-3.8582$ & 0.8792 \\
\hline Below $80 \%$ & 19 & $12(63.1)$ & $7(36.9)$ & 1.1020 & & \\
\hline \multicolumn{7}{|l|}{ FVC } \\
\hline Above $80 \%$ & 29 & $18(62)$ & $11(38)$ & 1 & $0.2546-3.7558$ & 0.9739 \\
\hline Below $80 \%$ & 13 & $8(61.5)$ & $5(38.5)$ & 0.9778 & & \\
\hline \multicolumn{7}{|l|}{ DC in 6MWT } \\
\hline Above/equal to the predicted & 22 & $13(60)$ & $9(40)$ & 1 & $0.3678-4.4949$ & 0.6939 \\
\hline Below the predicted & 20 & $13(65)$ & $7(35)$ & 1.2857 & & \\
\hline
\end{tabular}

$\%=$ relative frequency; $95 \% \mathrm{Cl}=95 \%$ confidence interval; $\mathrm{DC}$ in $6 \mathrm{MWT}=$ distance covered in the 6 -minute walk test; $F E V_{1}=$ forced expiratory volume in the first second; $\mathrm{FVC}=$ forced vital capacity; $\mathrm{n}=$ absolute frequency; $\mathrm{OR}=$ odds ratio.

* Univariate logistic regression.

\section{Discussion}

The close relationship between breathing and posture is a consensus in the management of CF. Postural disorders are considered secondary to pulmonary disease. In this context, this study sought to assess the impact of increased thoracic kyphosis in pulmonary function parameters (spirometry) and functional capacity (6MWT) of children and adolescents with CF.

The identification of the high prevalence of thoracic kyphosis in the studied population of children and adolescents with CF corroborates findings and conclusions that the literature presents. The pathophysiological process and the progression of pulmonary disease are pointed as having the major responsibility for the development of alterations in body posture. This is because the disease progression with pulmonary hypersecretion leads to hyperinflation and frequent coughing episodes. These events have repercussions on the musculoskeletal system through important muscle shortenings. The shortenings are able to cause postural changes that can alter the respiratory mechanics. ${ }^{2}$

This relationship between posture and respiratory mechanics has been the focus of discussion by various authors. ${ }^{2,4,16-20}$ According to them, air trapping is caused by recurrent inflammation, bronchial hypersecretion and decreased elastic recoil of the airways. These factors result in a remodeling of this structure, followed by chronic infection, with a consequent reduction of airway diameter and loss of lung elasticity. The hyperinflated thorax elevates the upper thorax and flattens the diaphragmatic domes. Such compensations raise the thoracic volume and the negativity of the pleural pressure, increasing transpulmonary pressure and airway diameter. The inspiratory muscles gradually adapt to the new position of the bone structure, which will lead to a shortening of the fibers and a reduction of these muscles' ability to generate strength. ${ }^{2,16}$ In individuals with poor nutritional status, the development of spinal deformities seems to be enhanced.

Given this pathophysiological process and its intimate connection with the rib cage, the posture alteration most commonly seen in CF is increased thoracic kyphosis. 4,17-21 This alteration was found in the present study, with a prevalence $(62 \%)$ similar to that found in the study by Parasa \& Maffulli. ${ }^{18} \mathrm{~A}$ lower incidence of around $15.1 \%$ had been published in the 1980s. 22

The high incidence of musculoskeletal complications in CF has been associated with increasing age and decreasing pulmonary function. $4,18,23$ Specifically on the posture, it is suggested that the presence of postural alterations has a correlation with reductions in lung function and in the capacity for physical exercise. 5,21,24 However, this was not observed in the current result, in which increased thoracic kyphosis was not related to spirometric data nor to 6MWT performance. The findings of Logvinoff \& Erkilla ${ }^{4,17}$ corroborate those presented here, because the kyphosis was also prevalent and had no correlation with the spirometric variables.

Some articles point to the decline in pulmonary function through important postural impairments, ${ }^{21}$ especially the increased thoracic kyphosis. ${ }^{23}$ Massie et al. ${ }^{23}$ showed that this type of change is associated with increased age and low pulmonary function, which is still controversial, since the study by Erkilla et al. did not find similar results. In it, thoracic deformity did not correlate with the severity of the disease or with pulmonary function, as it does not in the present study, although the prevalence of kyphosis 
increased with age. ${ }^{4}$

The association between the severity of cystic fibrosis and the impairment of posture does not follow a standard in the literature, just as the relationship between a worse posture and a worse pulmonary function. Unlike the findings presented here, as well as the study of Erkilla et al., ${ }^{4}$ Walshaw \& Tattersall ${ }^{21}$ found a correlation between posture and the severity of CF in adults. Denton et al. ${ }^{22}$ had found the same in 1981 with a sample of 91 children and adolescents, whose increased thoracic kyphosis was related to the severity of lung disease. The same behavior was published by Henderson \& Specter, ${ }^{20}$ which also found a correlation between the presence of kyphosis and age.

In the results obtained here, although, statistically, the influence of the severity of cystic fibrosis on pulmonary function of patients with increased thoracic kyphosis was not found, the second logistic regression analysis, even in the absence of this thoracic deformity, children with lesser severity showed higher values of FEV ${ }^{1}$ and FVC compared to the more severe patients $(95.6 \pm 12.2$ versus $74.1 \pm 21.9$, $p=0.027$, and $97.6 \pm 13.2$ versus $79.8 \pm 18,7, p=0.027$ ). Thus, irrespective of the posture, the worsening in disease severity is related to worsening pulmonary function. This probably is associated to the fact that clinical deterioration determines the progression of lung disease.

In contrast, the study by Tejero Garcia et al. ${ }^{19}$ found, in a sample of 50 CF patients aged over 16 years, a correlation of disease severity with $\mathrm{FEV}_{1}, \mathrm{FVC}$ and increased thoracic

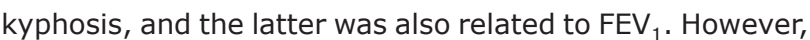
this study was a sample of spirometry values lower than those presented here, as well as with an older population. Moreover, disease severity was classified by the spirometry data only and not by the broad SS, as done in the current investigation. All these factors may have influenced the difference in results between studies. Another divergent finding in the study by this author is due to the correlation found between the severity of the disease and the DC in 6MWT, an event that did not happen here, since it was observed that the older the subject, the higher is the DC in 6MWT. There was no statistically significant difference in DC in 6MWT between groups of greater and lesser severity, in patients with and without thoracic kyphosis $(p=0.616$ and $\mathrm{p}=0.068$, respectively).

According to literature, the development of thoracic kyphosis has many causes. Among the factors that contribute to this deformity are: reduction of muscle mass, ${ }^{25}$ of bone mineral density, ${ }^{26}$ excessive respiratory effort, ${ }^{22}$ osteopenia ${ }^{24}$ and chronic pain. ${ }^{26}$

Its presence is often reported in publications on adult cystic fibrosis populations with a high percentage identified already in the pubertal phase, ${ }^{27}$ as is the profile of this study's sample. And, according to Elkin, 27 even if those individuals do not have repercussions on lung function yet, there is a need for an early multiprofessional intervention. Lannefors et al. ${ }^{28}$ emphasize this preventive idea, considering that there is a high prevalence of increased thoracic kyphosis that can be reversed if treated properly. According to the author, the maintenance of postural alignment reduces the risk of low back pain and spinal complications, besides contributing to the preservation of physical function. 28

Longitudinal studies show that the treatment of postural disorders can be successful through assessment methods and appropriate programs. ${ }^{16,21}$ Exercises for thoracic mobility, muscle stretching and coordination activities to promote improved posture and chest wall compliance, resulting in the maintenance and optimization of pulmonary function. Patients with more severe pulmonary disease, lower aerobic capacity and more sedentary lifestyles deserve special attention because they are predisposed to lower bone mineral density, higher prevalence of vertebral fracture and development of major thoracic kyphosis increases. ${ }^{19}$

Although the logistic regression analysis was not statistically significant for any of the variables, the odds ratio value of the variables DC in 6MWT and $\mathrm{FEV}_{1}$ show a tendency for the presence of kyphosis to be a risk factor for lower performance on the 6MWT and for lower spirometric value. A larger sample could sensitize statistical tests and contribute to the identification of new results.

The absence of a larger sample, characterized by patients more severely impaired and older, may have restricted the identification of results, as well as the application of a more sensitive instrument of postural assessment. Studies with longitudinal design to assess the evolution of thoracic deformity and the effect of therapeutic interventions, both in the musculoskeletal and respiratory systems, are suggestions for future supplementary investigations.

\section{Conclusion}

There was a high prevalence of increased thoracic kyphosis in children and adolescents with CF. This deformity did not alter pulmonary function and functional capacity and was not related to the severity of the disease. However, regardless of posture, the worsening in disease severity caused a greater decline in pulmonary function.

\section{References}

1. Dodge JA, Lewis PA, Stanton M, Wilsher J. Cystic fibrosis mortality and survival in the UK: 1947-2003. Eur Respir J. 2007;29:522-6.

2. Kraemer R, Baldwin DN, Ammann RA, Frey U, Gallati S. Progression of pulmonary hyperinflation and trapped gas associated with genetic and environmental factors in children with cystic fibrosis. Respir Res. 2006;7:138. 
3. Hodges PW, Heijnen I, Gandevia SC. Postural activity of the diaphragm is reduced in humans when respiratory demand increases. J Physiol. 2001 (Pt 3);537:999-1008.

4. Lannefors L. Influences on posture. Eighteenth Annual North American Cystic Fibrosis Conference, St Louis, MO. Pediatr Pulmonol. 2004;27:155-6.

5. Erkkila JC, Warwick WJ, Bradford DS. Spine deformities and cystic fibrosis. Clin Orthop Relat Res. 1978;131:146-50.

6. Massery M. Musculoskeletal and neuromuscular interventions: a physical approach to cystic fibrosis. J R Soc Med. 2005;98 Suppl 45:55-66.

7. Kanga J, Kuhn R, Craigmyle L, Haverstock D, Church D. Cystic fibrosis clinical score: a new scoring system to evaluate acute pulmonary exacerbation. Clin Ther. 1999;21:1343-56.

8. Hafen GM, Ranganathan SC, Robertson CF, Robinson PJ. Clinical scoring systems in cystic fibrosis. Pediatr Pulmonol. 2006;41:602-17.

9. Santos CI, Ribeiro JD, Ribeiro AF, Hessel G. Análise crítica dos escores de avaliação de gravidade da fibrose cística: estado da arte. J Bras Pneumol. 2004;30:286-98.

10. Althoff SA, Heyden SM, Robertson LD. Posture screening: a program that works. J Phys Educ Recreat. 1988;59:26-32.

11. Santos JB, Moro AR, Cezar MR, Reis PF, Luz JD, Reis DC. Descrição do método de avaliação postural de Portland State University. Fisioter Brasil. 2005;6:392-5.

12. ATS Committee on Proficiency Standards for Clinical Pulmonary Function Laboratories. ATS statement: guidelines for the sixminute walk test. Am J Respir Crit Care Med. 2002;166:111-7.

13. Miller MR, Hankinson J, Brusasco V, Burgos $F$, Casaburi $R$, Coates A, et al. Standardisation of spirometry. Eur Respir J. 2005;26:319-38.

14. Priesnitz CV, Rodrigues GH, Stumpf C da S, Viapiana G, Cabral CP, Stein RT, et al. Reference values for the 6-min walk test in healthy children aged 6-12 years. Pediatr Pulmonol. 2009;44:1174-9.

15. Doershuk CF, Matthews LW, Tucker AS, Nudleman H, Eddy G, Wise $M$, et al. A 5 year clinical evaluation of a therapeutic program for patients with cystic fibrosis. J Pediatr. 1964;65:677-93.

16. Sandsund CA, Roughton M, Hodson ME, Pryor JA. Musculoskeletal techniques for clinically stable adults with cystic fibrosis: a preliminary randomised controlled trial. Physiotherapy. 2011;97:209-17.

17. Logvinoff MM, Fon GT, Taussig LM, Pitt MJ. Kyphosis and pulmonary function in cystic fibrosis. Clin Pediatr (Phila). 1984;23:389-92.
18. Parasa RB, Maffulli N. Musculoskeletal involvement in cystic fibrosis. Bull Hosp Jt Dis. 1999;58:37-44.

19. Tejero García S, Giráldez Sánchez MA, Cejudo P, Quintana Gallego E, Dapena J, García Jiménez R, et al. Bone health, daily physical activity, and exercise tolerance in patients with cystic fibrosis. Chest. 2011;140:475-81.

20. Henderson RC, Specter BB. Kyphosis and fractures in children and young adults with cystic fibrosis. J Pediatr. 1994;125:208-12.

21. Tattersall R, Walshaw MJ. Posture and cystic fibrosis. J R Soc Med. 2003;96 Suppl 43:18-22.

22. Denton JR, Tietjen R, Gaerlan PF. Thoracic kyphosis in cystic fibrosis. Clin Orthop Relat Res. 1981;155:71-4.

23. Massie RJ, Towns SJ, Bernard E, Chaitow J, Howman-Giles R, Van Asperen PP. The musculoskeletal complications of cystic fibrosis. J Paediatr Child Health. 1998;34:467-70.

24. Conway SP. Impact of lung inflammation on bone metabolism in adolescents with cystic fibrosis. Paediatr Respir Rev. $2001 ; 2: 324-31$

25. Elkin SL, Williams $L$, Moore $M$, Hodson $M E$, Rutherford OM. Relationship of skeletal muscle mass, muscle strength and bone mineral density in adults with cystic fibrosis. Clin Sci (Lond). 2000;99:309-14.

26. Botton E, Saraux A, Laselve H, Jousse S, Le Goff P. Musculoskeletal manifestations in cystic fibrosis. Joint Bone Spine. 2003; 70:327-35

27. Elkin SL, Fairney A, Burnett S, Kemp M, Kyd P, Burgess J, et al. Vertebral deformities and low bone mineral density in adults with cystic fibrosis: a cross-sectional study. Osteoporos Int. $2001 ; 12: 366-72$.

28. Lannefors L, Button BM, McIlwaine M. Physiotherapy in infants and young children with cystic fibrosis: current practice and future developments. J R Soc Med. 2004;97 Suppl 44:8-25.

\section{Correspondence:}

Renata Tiemi Okuro

Rua Barão de Cotegipe, 5, Bairro Vila Isabel

CEP 20560-080 - Rio de Janeiro, RJ - Brazil

Tel. : +55 (21) 8335.2856, +55 (21) 3344.0816

E-mail: re_okuro@yahoo.com.br 